\title{
O PROGRAMA “BOLSA FAMÍLIA" E SUA IMPORTÂNCIA PARA AS FAMÍLIAS EM SITUAÇÃO DE VULNERABILIDADE SOCIAL
}

Fabíola Santos Carvalho de SOUZA; Dimítri de Araújo COSTA²; Francisco de Assis da SILVA ${ }^{3}$

\begin{abstract}
${ }^{1}$ Graduada em Serviço Social/Universidade Federal da Paraíba (UFPB); Especialista em Serviço Social e Políticas de Proteção Social/Centro Integrado de Tecnologia e Pesquisa (CINTEP), Brasil. E-mail: fabiolacarvalho2012@bol.com.br

${ }^{2}$ Bacharel e Licenciado em Ciências Biológicas/UFPB; Mestre em Ecologia e Monitoramento Ambiental/UFPB; Doutorando em Desenvolvimento e Meio Ambiente (PRODEMA)/UFPB, Brasil. E-mail: costa.researcher@yahoo.com.br

${ }^{3}$ Bacharel em Ecologia/UFPB; Mestre em Desenvolvimento e Meio Ambiente (PRODEMA)/UFPB, Brasil. Email: assismandela@gmail.com
\end{abstract}

Resumo. Esse estudo buscou verificar, por meio de levantamento bibliográfico, os aspectos gerais do programa "Bolsa Família" e se ocorreu de fato a melhoria das condições de vida. Foi verificado também o acesso aos serviços básicos como saúde e educação, além de refletir se os aspectos quantitativos foram suficientes para expandir suas capacidades e ter acesso a melhores oportunidades de vida e proporcionar melhorias aos beneficiários no futuro. Este programa constitui uma política pública de alta relevância em todo o território brasileiro, promovendo a redução da pobreza em famílias com vulnerabilidade socioeconômica. Esta política pública deve ser aprimorada e ampliada para reduzir os efeitos da desigualdade social, buscando inserir os beneficiários no contexto econômico, juntamente com incentivos para a geração de emprego e renda.

Palavras Chave: Desigualdade social; Efeito estigma; Emancipação feminina.

\section{THE "BOLSA FAMÍLIA" PROGRAM AND ITS IMPORTANCE FOR FAMILIES IN THE SITUATION OF SOCIAL VULNERABILITY}

Abstract. This study sought to verify, through a bibliographical survey, the general aspects of the "Bolsa Família" program and whether in fact the improvement of living conditions occurred. Access to basic services such as health and education was also verified, as well as to reflect whether the quantitative aspects were sufficient to expand their capacities and have access to better life opportunities and to provide improvements to beneficiaries in the future. This program constitutes a public policy of high relevance throughout Brazilian territory, promoting the reduction of poverty in families with socioeconomic vulnerability. This public policy must be improved and expanded to reduce the effects of social inequality, seeking to insert the beneficiaries in the economic context, along with incentives to generate employment and income.

Keywords: Social inequality; Stigma effect; Female emancipation. 


\section{EL PROGRAMA "BOLSA FAMÍLIA" Y SU IMPORTANCIA PARA LAS FAMILIAS EN SITUACIÓN DE VULNERABILIDAD SOCIAL}

Resumen. Este estudio buscó verificar, por medio de levantamiento bibliográfico, los aspectos generales del programa "Bolsa Família" y si ocurrió de hecho la mejora de las condiciones de vida. Se verificó también el acceso a los servicios básicos como salud y educación, además de reflejar si los aspectos cuantitativos fueron suficientes para expandir sus capacidades y tener acceso a mejores oportunidades de vida y proporcionar mejoras a los beneficiarios en el futuro. Este programa constituye una política pública de alta relevancia en todo el territorio brasileño, promoviendo la reducción de la pobreza en familias con vulnerabilidad socioeconómica. Esta política pública debe ser mejorada y ampliada para reducir los efectos de la desigualdad social, buscando insertar a los beneficiarios en el contexto económico, junto con incentivos para la generación de empleo y renta.

Palabras clave: Desigualdad social; Efecto estigma; Emancipación femenina.

\section{INTRODUÇÃO}

O Programa "Bolsa Família" (PBF) é um programa de assistência social que beneficia mais de 12,8 milhões de famílias, movimentando anualmente mais de R \$13,4 bilhões, contando com a adesão formal de todos os municípios brasileiros. Depois do período de estruturação, o PBF tem se expandido e apresentado resultados bem expressivos (SCHMIDT, 2006).

Assim, este trabalho visa analisar o PBF como uma ferramenta de fomento para famílias de comunidades menos favorecidas, sendo este programa uma política empoderadora dos direitos de cidadão, procurando refletir com a redução de pobreza e emancipação da mulher em sua realidade social (SCHMIDT, 2006).

Em nossos dias, a pobreza tem sido a origem de muitas situações de desequilíbrio social das comunidades menos favorecidas, afetando, dentre todos destas comunidades, principalmente a mulher e seu papel dentro da família. Por isso, programas de apoio, como o bolsa família, desenvolvem um papel importante e fundamental que é prioritário procurar entender e com isso, ampliar seus benefícios e alcance (GIDDENS, 1999).

O governo do ex-presidente Fernando Henrique Cardoso, instituiu alguns Programas de Proteção Social em prol das famílias mais necessitadas, como o programa "Bolsa Escola" e o programa "Bolsa Alimentação" (KLEIN, 2005). Estes contribuíam para a minimização da pobreza e objetivava a erradicação do trabalho infantil (SENNA et al., 2007). Em 2003, ocorreu a unificação dos planos e este passou a se chamar "Bolsa Família" (SENNA et al., 2007).

Desta maneira, os dois objetivos básicos deste programa são: a) transferir de forma eficiente a renda para as famílias com maior vulnerabilidade econômica, e b) proporcionar o 
rompimento do ciclo de transmissão da pobreza (SOARES; RIBAS; OSÓRIO, 2007; KLEIN, 2005).

No entanto, seguindo duas vertentes opostas, como poderíamos avaliar a importância deste plano? Autores como Santana (2007) e Senna et al. (2007) refletem posições opostas que chamam a atenção e requerem uma explicação. Enquanto, por um lado, se fala que o Bolsa Família é "um processo de emancipação que parte da família, articula com a comunidade, sendo este um a ponte para um alvo e não um fim, propriamente dito" (SANTANA, 2007, p. 6); por outro lado falasse da fragilidade exposta pelas denúncias públicas da ação de desenvolvimento e acompanhamento social do programa (SENNA et al., 2007).

Durante a existência deste programa pode-se observar que ocorreu uma redução da desigualdade social, embora não sendo o suficiente para retirar as famílias da pobreza (SOARES; RIBAS; OSÓRIO, 2007).

Caso os programas de transferências de renda centralizem no atendimento das pessoas com vulnerabilidade socioeconômica, envolvendo as condicionalidades como mecanismo de emancipação destas, como também ao acesso aos serviços públicos básicos (e.g. educação e saúde) e colaborar com o aumento da cidadania, estes programas serão, desta forma, eficazes e alcançarão seus objetivos dentro da política social (KERSTENETZKY, 2009).

Segundo Silva (2007), este programa, no lugar de ser um distribuidor, deveria ser um redistribuído de renda entre a população brasileira e que por este, observa-se que os resultados acabam sendo modestos frente a necessidade de superação da pobreza e da fome no Brasil.

Levando em conta a grande importância que este programa apresenta, se faz necessário que se avalie os resultados obtidos e possa realizar os ajustes necessários, para que os atendidos por este programa possam atingir, também, a geração de renda, estratégias políticas, sociais e educativas, objetivando quebrar o ciclo da pobreza crônica (SENNA et al., 2007).

Esse estudo buscou verificar, por meio de levantamento bibliográfico, os aspectos gerais do programa Bolsa Família e se ocorreu de fato a melhoria das condições de vida. Foi verificado também o acesso aos serviços básicos como saúde e educação, além de refletir se os aspectos quantitativos foram suficientes para expandir suas capacidades e ter acesso a melhores oportunidades de vida e proporcionar melhorias aos beneficiários no futuro.

Desta forma, este trabalho objetiva compreender e avaliar se o programa Bolsa Família tem conseguido atingir seus objetivos: melhorar as condições de vida das famílias 
mais vulneráveis e contribuir para que elas tenham acesso a direitos básicos como a educação e saúde.

\section{MATERIAL E MÉTODOS}

O presente trabalho teve como método o estudo comparativo, por meio de levantamento bibliográfico, buscando comparar dados entre gêneros e diferentes grupos. Para Gil (2002), o método comparativo é definido como aquele que se dá pela investigação de indivíduos, classes, fenômenos ou fatos, cuja finalidade é ressaltar as diferenças entres estes. Assim, o estudo analisou as condições de vida das famílias beneficiárias do Programa Bolsa Família.

\section{RESULTADOS E DISCUSSÃO}

\section{Breve histórico da Assistência Social no Brasil}

A seguir, um breve histórico da Assistência Social no Brasil, baseado no livro de Berenice Couto e colaboradores (COUTO et al., 2014) e no portal eletrônico do Ministério do Desenvolvimento Social (MDS, 2017):

O marco inicial da Assistência Social como campo de ação governamental no Brasil foi no ano de 1937, com a criação do Conselho Nacional de Serviço Social (CNSS). Na década seguinte, foi desenvolvida a Legião Brasileira de Assistência (LBA).

Com o intuito de centralizar a atuação federal em caráter exclusivo, foi elaborado o Ministério da Previdência e Assistência Social, no ano de 1977. Posteriormente, com a promulgação da Carta Magna em 1988, houve o reconhecimento da assistência social como dever de Estado no campo da seguridade social, deixando de ser complementar à Previdência.

Na década de 1990 ocorreram vários avanços, culminando em 1993, com a aprovação da Lei Orgânica da Assistência Social (LOAS), por meio de articulações entre os gestores municipais, estaduais e organizações não-governamentais (ONGs) com o Governo Federal. Inicia-se, desde então, o desenvolvimento de uma gestão pública e participativa da Assistência Social, por meio de conselhos deliberativos e paritários, no âmbito municipal, estadual e federal. Em seguida, no ano de 1997, foi editada a Norma Operacional Básica (NOB), que consolidou o sistema participativo e descentralizado, ampliando as atribuições dos entes federativos, além de instituir a obrigatoriedade de Conselho, Fundo e Plano Municipal de Assistência Social, como requisito para que o município adquirisse recursos federais.

Em 1998, com a nova edição da NOB, houve uma distinção entre projetos, serviços e programas; ocorreu o aumento das competências dos Conselhos de Assistência Social; e 
criação dos espaços de pactuação e negociação, que são as Comissões Intergestores Bipartite e Tripartite (CIBs e CITs, respectivamente), englobando representantes municipais, estaduais e federais de Assistência Social.

O ex-presidente da República Luís Inácio Lula da Silva instituiu, em 2004, o Ministério do Desenvolvimento Social e Combate à Fome, o qual foi efetivo na elaboração do Sistema Único de Assistência Social (Suas), que foi colocado em prática no ano seguinte. Também em 2004, foi editado o Plano Nacional de Assistência Social.

\section{Sistema Único de Assistência Social}

De acordo com o portal eletrônico do Ministério do Desenvolvimento Social (MDS, 2015), o "Suas" é um sistema com a participação da União, Distrito Federal, estados e municípios. A União tem a responsabilidade de formular, apoiar, articular e coordenar as ações. Enquanto isso, os estados realizam a gestão da Assistência Social dentro dos limites de sua competência, no qual suas atribuições são definidas na NOB/Suas.

Em relação à gestão do DF e municípios, há três possíveis níveis de habilitação ao "Suas", i.e. inicial, básico e pleno. A primeira é de competência dos municípios que atendam a algumas condições, e.g. funcionamento e existência de conselho, fundo e planos municipais de Assistência Social, como também da execução das ações da Proteção Social Básica com recursos próprios. Em relação ao nível básico, há uma autonomia do município para gerir a proteção social básica. Finalmente, no nível pleno, ocorre a gestão total das ações socioassistenciais por parte do referido ente federativo (MDS, 2015).

Por meio da CIT e CIBs ocorre a interlocução entre os entes, no qual a CIT corresponde há um ambiente de expressão e articulação das demandas dos gestores públicos, mantendo-se em contato com as CIBs, objetivando permutar informações sobre o desenvolvimento da descentralização. Assim, a CIT pactua e negocia sobre aspectos operacionais da gestão do "Suas" (MDS, 2015).

As instâncias estaduais da assistência social (as CIBs) realizam a conexão dos gestores, apresentando representantes do Estado e municípios, com o intuito de negociar os aspectos da gestão e organização do Sistema Estadual de Assistência Social, resguardando-se nas deliberações do Conselho Estadual de Assistência Social, nas orientações da CIT, no Conselho Nacional de Assistência Social (CNAS), e na legislação vigente. Além disso, as pactuações firmadas são enviadas ao Conselho Estadual para ciência, avaliação e/ou deliberação, como também encaminhadas ao CNAS, CIT e conselhos municipais para conhecimento (MDS, 2015). 


\section{Pré-requisitos e Condicionalidades do Programa}

De acordo com o Ministério de Desenvolvimento Social e Combate à Fome (2007), “os critérios de elegibilidade do Bolsa Família partem da definição de situação das famílias na pobreza, com ocorrência de crianças até 15 anos de idade, gestantes e nutrizes, e famílias em extrema pobreza, com ou sem ocorrência de crianças, gestantes e nutrizes” (MDS, p. 19, 2007).

Em relação às condicionalidades, o Programa determina que a família receptora do benefício cumpra algumas exigências, que compreende a manutenção das crianças e adolescentes em idade escolar para permanecerem no convívio educacional, bem como mantê-las sob os cuidados básicos de saúde, i.e. calendário de vacinação para as crianças de 0 a 6 anos, e agenda pré e pós-natal para as gestantes e lactantes (MDS, 2007).

Para o recebimento deste benefício, deve-se observar as condições financeiras, i.e. as famílias de pobreza e extrema pobreza, com renda per capita familiar mensal de 170 reais e 85 reais, respectivamente (BRASIL, 2016).

“As famílias em situação de pobreza e extrema pobreza podem ter maior dificuldade de acesso e de frequência aos serviços de Saúde. Por este motivo, o objetivo das condicionalidades do Programa é garantir a oferta das ações básicas, e potencializar a melhoria da qualidade de vida das famílias e contribuir para a sua inclusão social” (DAB, 2012).

As famílias que são elegíveis ao Benefício Variável à Gestante (BVG) é realizada pela saúde, através do Sistema de Gestão do Programa Bolsa Família na Saúde. Por meio deste auxílio ocorre o aumento da responsabilidade do Sistema Único de Saúde (SUS) com as famílias participantes do Bolsa Família, promovendo a ampliação da proteção ao bebê (e.g. inclusão do pré-natal) e à mãe, além de elevar a renda familiar na primeira infância e na gestação (DAB, 2012).

\section{Investimento do Governo Federal em geração de emprego e renda}

De acordo com o Portal Brasil (2013), por meio do Programa Bolsa Família foram gerados e mantidos 807 mil empregos e ocupações na região Nordeste, promovendo o aumento da arrecadação tributária nas outras regiões do Brasil, pois as pessoas que recebem este auxílio procuram aumentar o consumo de bens e serviços no âmbito nacional, fortalecendo o mercado interno.

“Segundo o diretor de Desenvolvimento Sustentável e Microfinança do BNB, Stélio Gama, beneficiários do Bolsa Família representam 45\% e 65\% do total de clientes dos 
programas de microcrédito urbano e rural do Banco do Nordeste, respectivamente Crediamigo e Agroamigo" (PORTAL BRASIL, 2013).

Os beneficiários também são incentivados a ter o seu próprio negócio de geração de renda, tornando-se Empreendedores Individuais (EI), caracterizando um mecanismo de inclusão na cadeia produtiva e um instrumento de acesso ao mercado formal. Desta forma, as pessoas só deixarão de receber o benefício caso a renda mensal per capita ultrapasse o teto do auxílio. Caso necessite, a pessoa que sair do programa terá prioridade para receber o complemento de renda (PORTAL DO DESENVOLVIMENTO LOCAL, 2017).

Os beneficiários do programa têm a prioridade e são incentivados a ingressar em um dos cursos profissionalizantes do PRONATEC fornecidos pelo Governo Federal e pelos Estados. Esses cursos gratuitos objetivam capacitar os participantes, qualificando-os para novas oportunidades de trabalho (BOLSA FAMÍLIA, 2017).

Normalmente, as pessoas que recebem este auxílio de transferência de renda optam pelos cursos de curta duração (i.e. Formação Inicial e Continuada ou Qualificação Profissional de Trabalhadores) e com maior demanda do mercado de trabalho (PRONATEC, 2017).

Os beneficiários que pretendam ingressar em um desses cursos devem dirigir-se a uma unidade do Centro de Referência da Assistência Social (CRAS) para realizar sua inscrição. Por intermédio do CRAS, a pessoa será encaminhada para uma instituição de ensino conveniada (BOLSA FAMÍLIA, 2017).

\section{Efeito Estigma}

Percebemos um grande preconceito que foi desenvolvido dentro da sociedade sobre os beneficiários que recebem auxílio de programas de transferência de renda, que pode estar associada a desutilidade ao receber este benefício. O resultado gerado por este fato acarreta no "efeito estigma" (MOFFITT, 1983). Muitas pessoas podem estar desempregadas decorrentes deste efeito (WASGROVE, 1987), e podem permanecer dependentes do programa de transferência por longo tempo (PAGE, 1984).

No entanto, Mattos e Ponczek (2009) analisando dados da Pesquisa Domiciliar realizada em 2005 com os beneficiários do Bolsa Família, constataram que a pessoa "estigmatizada" possui menor probabilidade de permanecer desempregado, ou de apresentar alguém na família que se tornou desempregado. Assim, estes indivíduos buscam melhorias em suas condições de vida e desvinculam-se do programa, desviando dos pensamentos preconceituosos das pessoas (MATTOS e PONCZEK, 2009). 
Além disso, este benefício social implica positivamente na oferta de trabalho para as mães, que são responsáveis pelo recebimento na maioria dos casos, pois pode atuar na mudança de atitude das mesmas perante o "estigma" de participar do programa (e.g. TAVARES, 2010). Este efeito estigma é a discriminação a qual a beneficiária sofre, tanto por ela mesma, quanto pelos outros que a julgam. No entanto, tal efeito pode estimular a procura por novos empregos, como também a queda dos índices de desemprego para as famílias beneficiadas pelo programa (MATTOS e PONCZEK, 2009).

\section{CONCLUSÕES}

Observa-se que o Programa Bolsa Família corresponde a uma das maiores ações de transferência de renda, no Brasil e no mundo. As políticas públicas de transferências sociais direcionadas aos mais necessitados representam uma importante funcionalidade para o dinamismo da macroeconomia brasileira (CRONEMBERGER; TEIXEIRA, 2013), minimizando os efeitos da desigualdade social e da pobreza.

Diante da realidade apresentada, constata-se que o referido programa de distribuição de renda possui uma importância fundamental na renda das famílias com grande vulnerabilidade socioeconômica. Portanto, esta política pública deve ser aprimorada e ampliada para reduzir os efeitos da desigualdade social, buscando inserir os beneficiários no contexto econômico, juntamente com incentivos para a geração de emprego e renda. Nesse contexto, o governo, em todos os âmbitos (municipal, estadual e federal), necessita investir nas áreas básicas, como educação e saúde, objetivando melhorar as condições de vida de toda a população brasileira.

Por outro lado, a baixa capacidade do governo em promover geração de emprego e renda resulta em um aspecto negativo no programa, "uma vez que não há uma diretriz clara pautada na intersetorialidade e intergovernabilidade para atuar sobre as causas da precariedade de inserção da população adulta no circuito produtivo" (SENNA et al., 2007, p. 93).

Além disso, a população menos favorecida, uma vez contemplada com a inserção no Programa, teria que ter outros estágios sociais que lhes contemplaria com a ascensão da atual realidade social e lhe proporcionaria um avanço socioeconômico, contribuindo para o seu engrandecimento pessoal e familiar, passando a fazer parte de uma classe trabalhadora e com aspirações de melhorias, não apenas temporária, mas sim, com reflexos entre seus familiares de cunho duradouro. Porém, na atual realidade que o Brasil passa, está complementação esperada não tem ocorrido de forma necessária, atravancando o desenvolvimento esperado e 
frustrando as mesmas famílias que tanto necessitam desta ascensão, além da própria expectativa da nação quanto a eficiência deste programa.

\section{AGRADECIMENTOS}

Os autores agradecem ao apoio institucional do Centro Integrado de Tecnologia e Pesquisa. D.A.C. agradece pela bolsa de doutorado fornecida pela Fundação de Apoio à Pesquisa do Estado da Paraíba (FAPESQ) em parceria com a Coordenação de Aperfeiçoamento de Pessoal de Nível Superior (CAPES).

\section{REFERÊNCIAS}

BOLSA FAMÍLIA. Cursos profissionalizantes gratuitos para quem recebe Bolsa Família. 2017. Disponível em: <http://bolsafamilia.blog.br/educacao/cursos-profissionalizantesgratuitos/>. Acesso em: 21 jun. 2017.

BRASIL. Decreto $n^{\circ}$ 8.794, de 29 de junho de 2016. Altera o Decreto no 5.209, de 17 de setembro de 2004, que regulamenta a Lei no 10.836, de 9 de janeiro de 2004, que cria o Programa Bolsa Família, e o Decreto no 7.492, de 2 de junho de 2011, que institui o Plano Brasil Sem Miséria, e dá outras providências, Brasília, DF, 2016.

COUTO, B.R.; YAZBEK, M.C.; SILVA, M.O.S.; RAICHELIS, R. (Org.). O Sistema Único de Assistência Social no Brasil: uma realidade em movimento. São Paulo: Cortez, 2014.

CRONEMBERGER, I.H.G.M.; TEIXEIRA, S.M. Famílias vulneráveis como expressão da questão social e à luz da política de assistência social. Interface - Revista do Centro de Ciências Sociais Aplicadas, v. 9, n. 2, p. 92-117, 2013.

DePARtamento de ATENÇÃo BÁSICA (DAB). Programa Bolsa Família. 2012. Disponível em: <http://dab.saude.gov.br/portaldab/ape_bfa.php〉. Acesso em: 20 jun. 2017.

GIDDENS, A. A terceira via: reflexões sobre o impasse político atual e o futuro da socialdemocracia. Rio de Janeiro: Record, 1999.

GIL, A.C. Técnicas de pesquisa em economia e elaboração de monografias. 4 ed. São Paulo: Atlas, 2002. 
KERSTENETZKY, C.L. Redistribution and development? The political economy of the Bolsa Família Program. Dados - Revista de Ciências Sociais, v. 52, n. 1, p. 53-83, 2009.

KLEIN, C. A produção da maternidade no Programa Bolsa Família. Estudos Feministas, v. 13 , n. 1, p. 31-52, 2005.

MATTOS, E.; PONCZEK, V. O efeito do estigma sobre os beneficiários de programas de transferência no Brasil. Escola de Economia de São Paulo da Fundação Getúlio Vargas, São Paulo, texto 226, n. 1, 2009.

MINISTÉRIO DO DESENVOLVIMENTO SOCIAL (MDS). Gestão do Sistema Único de Assistência Social (Suas). 2015. Disponível em: <http://mds.gov.br/assuntos/assistenciasocial/gestao-do-suas>. Acesso em: 3 jul. 2017.

MINISTÉRIO DO DESENVOLVIMENTO SOCIAL (MDS). A história da Assistência Social Brasileira. $2017 . \quad$ Disponível em: <http://www.mds.gov.br/suas/conheca/conheca09.asp>. Acesso em: 3 jul. 2017.

MINISTÉRIO DO DESENVOLVIMENTO SOCIAL E COMBATE À FOME (MDS). Secretaria de Avaliação e Gestão da Informação. Avaliação de Políticas e Programas do MDS - Resultados: Volume 2 - Bolsa Família e Assistência Social. Brasília, 2007.

MOFFITT, R. An economic model of welfare stigma. The American Economic Review, v. 73, n. 5, p. 1023-1035, 1983.

PAGE, R. Stigma. London: Routledge and Keegan Paul, 1984.

PORTAL BRASIL. Bolsa Família gera 807 mil empregos por ano. 2017. Disponível em: <http://www.brasil.gov.br/economia-e-emprego/2013/11/bolsa-familia-gera-807-milempregos-por-ano>. Acesso em: 20 jun. 2017.

PORTAL DO DESENVOLVIMENTO LOCAL. O Empreendedor Individual e o Programa Bolsa Família - um caminho seguro. 2017. Disponível em: 
<http://www.portaldodesenvolvimento.org.br/o-empreendedor-individual-e-o-programabolsa-familia-um-caminho-seguro/>. Acesso em: 20 jun. 2017.

PROGRAMA NACIONAL DE ACESSO A CURSOS, EMPREGOS E CONCURSOS (PRONATEC). Inscrições, Cursos e Vagas. Saiba tudo sobre o Pronatec 2017. 2017. Disponível em: <http://pronatec.pro.br/>. Acesso em: 21 jun. 2017.

SANTANA, J.A. A evolução dos programas de transferência de renda e o Programa Bolsa Família. In: SEMINÁRIO POPULAÇÃO, POBREZA E DESIGUALDADE, 2007, Belo Horizonte. Resumos... p. 1-19.

SCHMIDT, J.P. Exclusão, inclusão e Capital social: O capital social nas ações de inclusão. In: LEAL, R.; REIS, J. R. Demandas sociais e políticas públicas. TOMO 6. Santa Cruz do Sul: EDUNISC, 2006.

SENNA, M. C. M.; BURLANDY, L.; MONNERAT, G. L.; SCHOTTZ, V.; MAGALHÃES, R. Programa Bolsa Família: nova institucionalidade no campo da política social brasileira. Revista Kátal, Florianópolis, v. 10, n. 1, p. 86-94, 2007.

SILVA, M.O.S. O Bolsa Família: problematizando questões centrais na política de transferência de renda no Brasil. Ciência \& Saúde Coletiva, Rio de Janeiro, v. 12, n. 6, p. 1429-1439, 2007.

SOARES, F.V.; RIBAS, R.P.; OSÓRIO, R.G. Avaliando o impacto do Programa Bolsa Família: uma comparação com programas de transferência de renda de outros países. IPC Evaluation Note, Brasília, dezembro, 2007.

TAVARES, P.A. Efeito do Programa Bolsa Família sobre a oferta de trabalho das mães. Economia e Sociedade, Campinas, v. 19, n. 3 (40), p. 613-635, 2010.

WASGROVE, D. Policing yourself: social closure and internalization of stigma. In: LEE, G.; LOVERIDGE, R. (Ed.). The Manufacture of Disavantage. Philadelphia: Open University Press, 1987. 